\title{
Role of FK506-binding protein 51 in the control of apoptosis of irradiated melanoma cells
}

\author{
S Romano', A D’Angelillo ${ }^{1}$, R Pacelli ${ }^{2}$, S Staibano ${ }^{3}$, E De Luna ${ }^{1}$, R Bisogni ${ }^{1}$, E-L Eskelinen ${ }^{4}$, M Mascolo ${ }^{3}$, G Cali ${ }^{5}$, C Arra ${ }^{6}$ and \\ MF Romano*,1
}

FK506-binding protein 51 (FKBP51) is an immunophilin with isomerase activity, which performs important biological functions in the cell. It has recently been involved in the apoptosis resistance of malignant melanoma. The aim of this study was to investigate the possible role of FKBP51 in the control of response to ionizing radiation (Rx) in malignant melanoma. FKBP51-silenced cells showed reduced clonogenic potential after irradiation compared with non-silenced cells. After Rx, we observed apoptosis in FKBP51-silenced cells and autophagy in non-silenced cells. The FKBP51-controlled radioresistance mechanism involves NF- $\kappa$ B. FKBP51 was required for the activation of Rx-induced NF- $\kappa$ B, which in turn inhibited apoptosis by stimulating X-linked inhibitor of apoptosis protein and promoting authophagy-mediated Bax degradation. Using a tumor-xenograft mouse model, the in vivo pretreatment of tumors with FKBP51-siRNA provoked massive apoptosis after irradiation. Immunohistochemical analysis of 10 normal skin samples and $\mathbf{8 0}$ malignant cutaneous melanomas showed that FKBP51 is a marker of melanocyte malignancy, correlating with vertical growth phase and lesion thickness. Finally, we provide evidence that FKBP51 targeting radiosensitizes cancer stem/initiating cells. In conclusion, our study identifies a possible molecular target for radiosensitizing therapeutic strategies against malignant melanoma.

Cell Death and Differentiation (2010) 17, 145-157; doi:10.1038/cdd.2009.115; published online 21 August 2009

Malignant melanoma is an aggressive neoplasm. The prognosis is bad in the advanced stages of the disease because of resistance to conventional anticancer treatments and the high metastatic potential of this tumor. Currently, no efficient therapeutic strategies are available to control the advanced disease. ${ }^{1}$ The use of radiotherapy, the most common antitumor treatment, is controversial for advanced melanoma; it serves mainly as a palliative treatment because of the tumor's radioresistance. In an attempt to elucidate the mechanism protecting malignant melanoma against the killing effect of ionizing radiation ( $\mathrm{Rx}$ ), we investigated the cellular response to $\mathrm{Rx}$ in different human melanoma cell lines.

The DNA damage response is complex and relies on the simultaneous activation of different networks. The response involves DNA damage recognition, repair, and the induction of signaling cascades leading to cell cycle checkpoint activation and stress-related responses. ${ }^{2,3}$ Apoptosis is a common biological mechanism for eliminating damaged cells involving the activation of enzymes known as caspases, and leading to endonuclease-mediated internucleosomal fragmentation of DNA. ${ }^{4}$ Type II cell death, induced by stress-inducing agents, is autophagy, 5,6 which is a process of intracellular bulk degradation in which cytoplasmic components, including organelles, are sequestered within double-membrane vesicles that deliver the contents to the lysosome/vacuole for degradation. ${ }^{7}$ It is controversial whether this recently discovered process causes death or, instead, protects cells. ${ }^{8}$ In fact, the products derived from autophagy are recycled to maintain essential cellular processes. However, there are several lines of evidence that support a role for autophagy in increasing the threshold for apoptosis, thereby sustaining cell survival under conditions of stress. ${ }^{9}$

Recently, our studies implicated the large immunophilin FK506-binding protein 51 (FKBP51) in the control of apoptosis induced in malignant melanoma by DNA-damaging agents, such as anthracyclin compounds. ${ }^{10}$ We previously showed that FKBP51 is essential for the NF- $\kappa$ B activation induced by doxorubicin. It is noted that NF- $\kappa$ B controls apoptosis at the genetic level and has been implicated in the radioresistance of melanoma. ${ }^{11,12}$ It is widely known that the $\mathrm{NF}-\kappa \mathrm{B}$ transcription complex belongs to the Rel family, which comprises five mammalian Rel/NF- $\kappa$ B proteins: RelA (p65), c-Rel, RelB, NF- $\kappa$ B1 (p50/p105), and NF- $\kappa$ B2 (p52/100). ${ }^{13}$ The activity of NF- $\kappa \mathrm{B}$ is controlled by cytoplasmic shuttling to

\footnotetext{
${ }^{1}$ Department of Biochemistry and Medical Biotechnology, Federico II University of Naples, Naples, Italy; ${ }^{2}$ Institute of Biostructure and Bio-Imaging, National Research Council (CNR), Naples, Italy; ${ }^{3}$ Department of Biomorfological and Functional Sciences, Pathology Section, Federico II University of Naples, Naples, Italy; ${ }^{4}$ Division of Biochemistry, Department of Biological and Environmental Sciences, University of Helsinki, Helsinki, Finland; ${ }^{5}$ Institute of Endocrinology and Experimental Oncology, Italian National Research Council (CNR), Naples, Italy and ${ }^{6}$ Italian National Cancer Institute, G. Pascale Foundation, Naples, Italy

${ }^{*}$ Corresponding author: MF Romano, Department of Biochemistry and Medical Biotechnologies, Federico II University, via Pansini, 5, 80131, Naples, Italy.

Tel: + 39081746 3125; Fax: + 39081746 3205; E-mail: romano@dbbm.unina.it

Keywords: FKBP51; NF- $\kappa$ B; apoptosis; autophagy; melanoma

Abbreviations: ABCG2, ATP-binding cassette subfamily G member 2; Becn-1, Beclin-1; CMM, cutaneous malignant melanoma; FKBP51, FK506 binding protein 51; $\mathrm{I}_{\kappa} \mathrm{B}$, inhibitor of $\kappa$-light-chain-enhancer of activated B cells; IKK, $\mathrm{I}_{\kappa} \mathrm{B}$ kinase complex; LC3, light chain 3; MFI, mean fluorescence intensity; NF- $\kappa \mathrm{B}$, nuclear factor of $\kappa$ light-chain-enhancer of activated B cells; NS, non-silencing; Rx, ionizing radiation; siRNA, short interfering RNA; xIAP, X-linked inhibitor of apoptosis protein; zVAD, zValine-Alanine-Aspartic acid

Received 09.6.09; revised 15.7.09; accepted 17.7.09; Edited by H Ichijo; published online 21.8.09
} 
the nucleus in response to cell stimulation. The NF- $\kappa$ B dimers containing RelA or c-Rel are retained in the cytoplasm through interaction with inhibitors $\left(I_{\kappa} \mathrm{BS}\right) .{ }^{14}$ In response to a variety of stimuli, $\mid \kappa$ Bs are phosphorylated by the activated $I_{\kappa} B$ kinase (IKK) complex, ubiquitinated, and degraded by the $26 \mathrm{~S}$ proteosome. $^{13,14}$ This process allows NF- $\kappa$ B dimers to translocate to the nucleus, where they stimulate the expression of multiple target genes. ${ }^{13-15}$

In this study, we attempted to investigate the role of FKBP51 in the activation of NF- $\kappa$ B by $\mathrm{Rx}$ and in the protection of tumor cells against Rx-induced killing, using different cell lines. Though we detected very low levels of apoptosis, we observed cellular events consistent with autophagy after cell irradiation. By downmodulating the FKBP51 level, we obtained the induction of massive apoptosis after irradiation, both in vitro and in vivo. We investigated the mechanism of apoptosis regulation and found that FKBP51 controlled radioresistance through the activation of $\mathrm{NF}-\kappa \mathrm{B}$. These results suggest that FKBP51 is a promising candidate target for radiosensitizing strategies against malignant melanoma. The translational implication of our findings is reinforced by the clinical evidence of clear immunoreactivity for FKBP51 in all skin samples of cutaneous malignant melanomas (CMMs) from 80 patients. Finally, our study provided evidence that silencing FKBP51 also radiosensitized cancer cells bearing stem markers, which is considered predictive of tumor radiocurability. ${ }^{16}$

\section{Results}

FKBP51 downmodulation sensitizes melanoma cells to $\mathbf{R x}$-induced apoptosis. To investigate the role of FKBP51 in the cellular response to $\mathrm{Rx}$, melanoma cells were transfected with a short interfering (si) RNA previously shown to efficiently downmodulate the protein. ${ }^{10}$ Figure 1 shows representative results of the effect of FKBP51 gene silencing in the SAN melanoma cell line. The downmodulating effect of FKBP51 siRNA was specific because it could not be reproduced by a siRNA for FKBP12 ${ }^{17}$ (Figure 1a). A clonogenic assay was performed using cells transfected with FKBP51 siRNA, non-silencing (NS) RNA, or nothing. Knocking down FKBP51 in melanoma cells produced a sensitizer enhancement ratio ${ }^{18}$ of $1.5(7.2 \mathrm{~Gy} /$ $4.8 \mathrm{~Gy})$. This ratio was calculated on the basis of the radiation dose necessary to obtain the end point of a $90 \%$ inhibition of colony formation. As shown in Figure 1b, the line corresponding to $10 \%$ survival intercepts the dose response curve of control cells (not transfected or transfected with NS RNA) at $7.2 \mathrm{~Gy}$, whereas that of FKBP51-depleted cells occurred at $4.8 \mathrm{~Gy}$. This result suggests that decreased levels of FKBP51 remarkably increase the cytotoxic effect of radiation in melanoma cells. To investigate the cellular response to $\mathrm{Rx}$ in cells depleted of FKBP51, the light chain 3 (LC3)-I to LC3-II conversion and levels of cleaved caspase-3, hallmarks of autophagy ${ }^{19}$ and apoptosis, ${ }^{4}$ respectively, were investigated by western blot. Whole cell lysates were prepared from cells transfected with the specific siRNA or NS RNA. At $48 \mathrm{~h}$ after transfection, cells were exposed to 4 Gy dose Rx and harvested at 0, 2, 4, 6, and 9h. Figure 1c shows that the presence of the autophagosome membrane recruited the LC3-II isoform in non-irradiated cells, both transfected and not transfected with FKBP51 siRNA, which is consistent with a basal level of autophagy. The isoform disappeared $6 \mathrm{~h}$ after $\mathrm{Rx}$ exposure in FKBP51-depleted cells but not in NS RNA-transfected cells. An increase in Beclin-1 (Becn-1) levels was detected in non-silenced cells after $4 \mathrm{~h}$, suggesting that this increase had a role in sustaining the LC3-I to LC3-II conversion. In contrast, the appearance of the active fragment of the execution caspases- 3 and $-7^{20}$ in FKBP51-depleted cells, as early as $4 \mathrm{~h}$ after $\mathrm{Rx}$ exposure, suggests the activation of apoptosis. Interestingly, Bax levels decreased in irradiated non-silenced cells, concomitant to increase of Becn-1 levels and LC3-I to LC3-II conversion. Autophagy was confirmed by transmission electron microscopy; a quantitation analysis of autophagic profiles/cell area showed a clear increase in autophagosomes $6 \mathrm{~h}$ after $\mathrm{Rx}$ exposure (Figure 1d). Apoptosis was confirmed by flow cytometry. Figure 1e shows the flow cytometric histograms of caspase- 9 and -3 activation, annexin $\mathrm{V}$ binding, and propidium iodide incorporation in irradiated cells. A measure of cell death by annexin $\mathrm{V}$ binding in 15 independent experiments clearly showed that $\mathrm{Rx}$ induced a remarkable increase in the cell death of FKBP51-depleted cells (48.7 \pm 11.8) compared with that of non-silenced cells $(26.7 \pm 8.1)$ $(P=0.000)$. The mean values of cell death for non-irradiated, non-silenced or silenced cells were $18.0 \pm 4.4$ and $27.9 \pm 8.5$, respectively $(P=0.022)$. This finding suggests that knocking down FKBP51 reduces the threshold for cell death. The induction of apoptosis in FKBP51-depleted cells was confirmed using the pan-caspase inhibitor z-Valine-AlanineAspartic Acid (zVAD), which clearly inhibited Rx-induced cell death (Figure 1f). The sensitizing effect of FKBP51 siRNA on $R x$-induced apoptosis was observed also in G361, A375, and SK-MEL-3 melanoma cell lines (not shown).

FKBP51 downmodulation prevents the $R x$-induced activation of NF- $\kappa$ B. Rx induces NF- $\kappa$ B activation. ${ }^{21}$ We found that the kinetics of $\mathrm{I} \kappa \mathrm{B}$ degradation showed a decrease in $1 \kappa \mathrm{B} \alpha$ levels and the complete disappearance of $\mathrm{l} \kappa \mathrm{B} \beta$ as early as $4 \mathrm{~h}$ after irradiation, with a return to the basal level after $20 \mathrm{~h}$ (Figure $2 \mathrm{a}$ ). The activation of $\mathrm{NF}-\kappa \mathrm{B}$ was confirmed by electrophoretic gel mobility shift assay (EMSA) (Figure $2 b$ ). According to our earlier findings, the treatment of cells with FKBP51 siRNA prevents both $\mathrm{l} \kappa \mathrm{B}$ degradation and the nuclear translocation of the transcription factor. In line with $\mathrm{NF}-\kappa \mathrm{B}$ activation, an increase in the level of the caspase inhibitor $X$-linked inhibitor of apoptosis protein (xIAP) was observed. As expected, such an increase was not observed in FKBP51-silenced cells (Figure 2c). Consistent with the notion that $x I A P$ transcription is under $\mathrm{NF}-\kappa \mathrm{B}$ control, ${ }^{15}$ reduced levels of XIAP mRNA, both basal and $\mathrm{Rx}$-induced, were found in p65-silenced cells compared with those in non-silenced cells (Figure $2 d$ ). The upregulation of XIAP had a role in the inhibition of irradiated melanoma cell apoptosis. In fact, when XIAP expression was silenced with siRNA, the Rx stimulated caspase activation and cell death (Figure 2e). Taken together, these findings suggest that FKBP51-silenced cells fail to activate NF- $\kappa$ B-controlled anti-apoptotic genes when irradiated. 
a

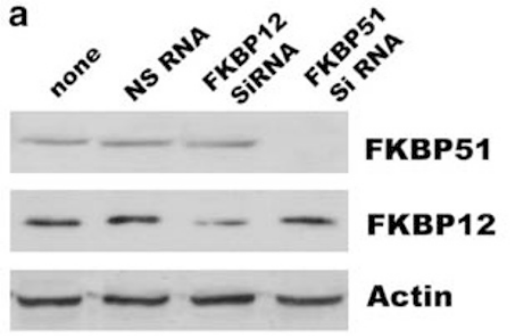

C

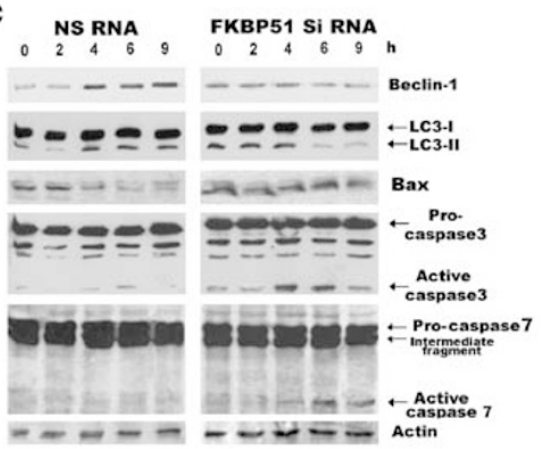

e
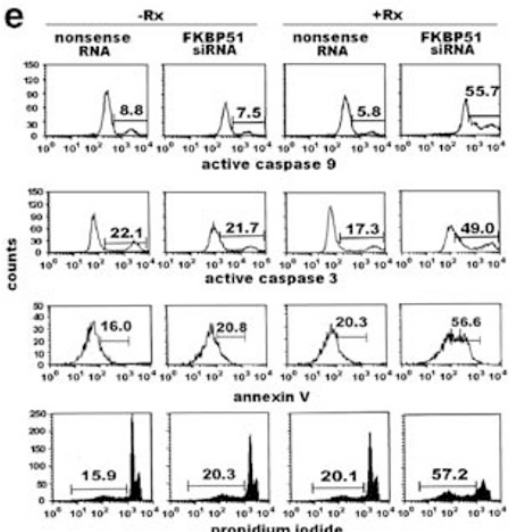

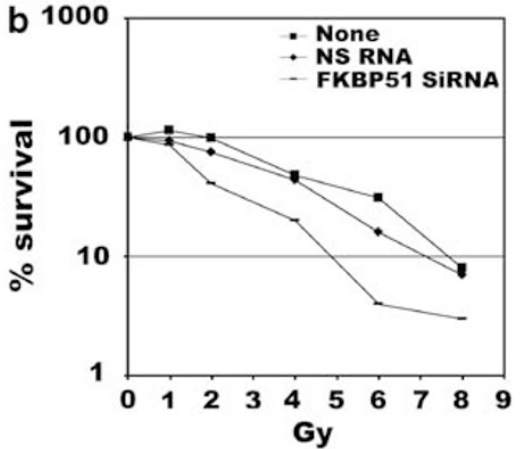

d
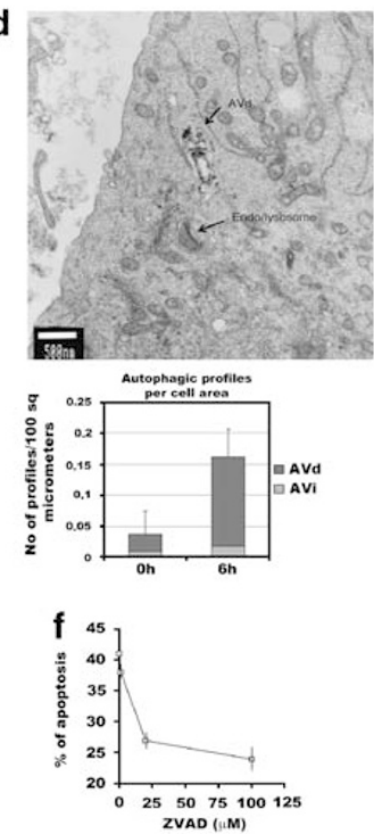

Figure 1 Activation of apoptosis in irradiated melanoma cells depleted of FKBP51. (a) Western blot assay of FKBP51 in cell lysates obtained from the melanoma cell line SAN transfected with FKBP51 siRNA, FKBP12 siRNA, or a non-silencing (NS) oligoribonucleotide as control. (b) Clonogenic assay of irradiated cells transfected with FKBP51 siRNA, NS RNA, or not transfected. Cells were irradiated with the indicated doses of ionizing radiation (Rx), harvested, and plated in triplicate. After 10 days, the colonies were stained with crystal violet and counted. (c) Western blot assay of Becn-1, LC3-II, Bax, caspase-3 and -7 in cell lysates prepared from melanoma cells transfected with FKBP51 siRNA or NS RNA. Cells were irradiated with $4 \mathrm{~Gy}$ Rx and harvested at the indicated times. (d) Transmission electron microscopy image of an irradiated melanoma cell, $6 \mathrm{~h}$ after exposure at a 4 Gy dose. Scale bar, $500 \mathrm{~nm}$. Graphic representation of autophagic profiles/cell area in non-irradiated $(0 \mathrm{~h})$ and irradiated $(6 \mathrm{~h})$ cells. AVd, degradative autophagic compartment; $\mathrm{AVi}$, initial autophagosome. (e) Flow cytometric histograms of active caspases -9 and -3 , annexin $\mathrm{V}$ binding, and the propidium iodide incorporation of SAN melanoma cells transfected with NS RNA or FKBP51 siRNA. Cells were irradiated with $4 \mathrm{~Gy} R \mathrm{Rx}$ and harvested after 6,48 , and $72 \mathrm{~h}$ to measure caspase activity, annexinV binding, and propidium iodide incorporation, respectively. (f) Graphic representation of the apoptosis of melanoma cells transfected with FKBP51 siRNA. At $48 \mathrm{~h}$ after transfection, cells were incubated with the indicated doses of ZVAD and irradiated with $4 \mathrm{~Gy} R \mathrm{Rx}$. After another $48 \mathrm{~h}$, cells were harvested and apoptosis was determined by annexin $\mathrm{V}$ staining

Rx-induced NF- $\kappa$ B sustains autophagy. To investigate whether the enhanced levels of Becn-1 were because of NF- $\kappa$ B activation, we attempted to downmodulate the p65 subunit of NF- $\kappa \mathrm{B}$. A supershift assay provided evidence that p65 represents the main component of the NF- $\kappa$ B complex activated by $R x$ in our cell system. As shown in Figure 3a, the Rx-induced NF- $\kappa$ B band was supershifted by anti-p50 and anti-p65 antibodies. Melanoma cells transfected with p65 siRNA or a NS RNA control were irradiated and, after $6 \mathrm{~h}$, total cell lysates were prepared. A western blot assay showed that p65 siRNA, but not NS RNA, downmodulated the protein (Figure $3 b$ ). Radiation treatment enhanced the levels of Becn-1 in non-silenced cells, but this was not observed in cells depleted of p65 (Figure $3 b$ ). An increase in the levels of the LC3-II isoform was found in irradiated cells but not when p65 was downmodulated (Figure $3 b$ ). The Rx-induced increase in Becn-1 protein was associated to increase in $B E C N-1$ mRNA levels (Figure 3c). Such increase was not observed in p65silenced cells (Figure $3 c$ ). This result suggests that p65 was essential for Becn-1 expression. Our finding is in accordance with the very recent demonstration that p65 


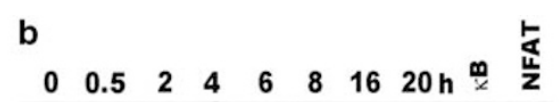
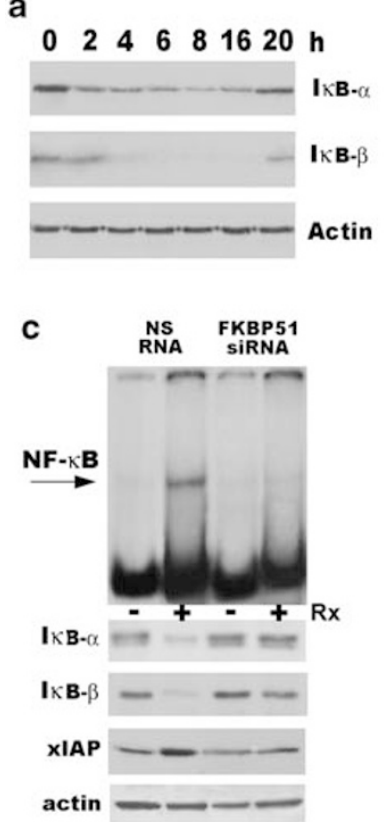

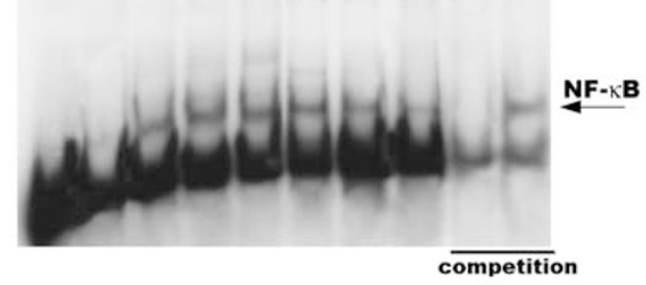

d

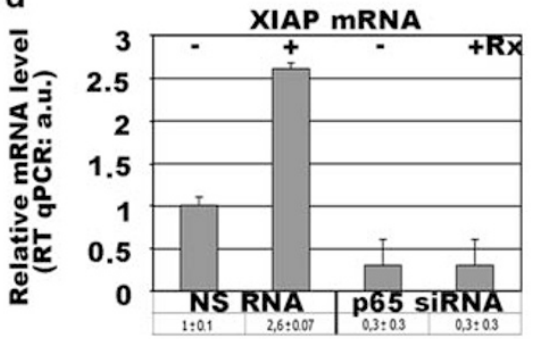

e

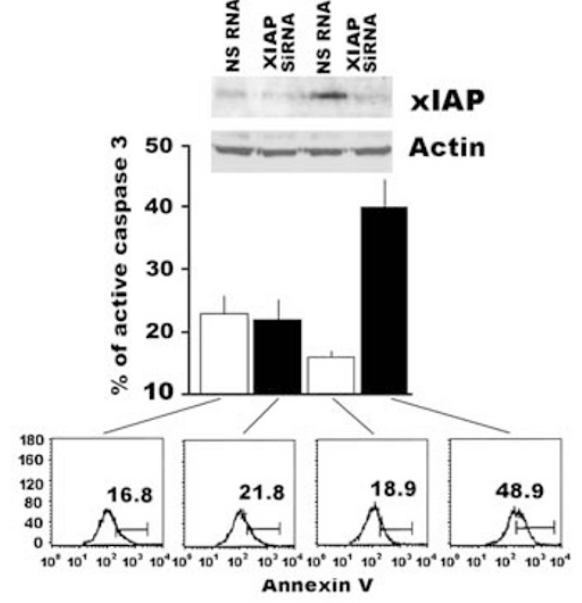

Figure 2 Lack of NF- $\kappa$ B activation and xIAP induction in melanoma cells depleted of FKBP51. (a) Western blot assay of $I_{\kappa} \mathrm{B} \alpha$ and $I_{\kappa} \mathrm{B} \beta$ levels in cytoplasmic extracts prepared from irradiated SAN melanoma cells harvested at the indicated times. (b) An electrophoretic mobility shift assay (EMSA) using nuclear extracts prepared from irradiated melanoma cells harvested at the indicated times. The last two lanes show a competition assay performed with the same $\kappa B$ cold oligonucleotide or an unrelated cold oligonucleotide (NFAT) that was added to the incubation mixture. (c) EMSA using nuclear extracts and western blot assay of whole cell lysates obtained from melanoma cells transfected with non-silencing (NS) RNA or FKBP51 siRNA. At $48 \mathrm{~h}$ after transfection, cells were irradiated with 4 Gy ionizing radiation (Rx) and, after an additional 6-h incubation, harvested for the preparation of both nuclear extracts and whole cell lysates. (d) Normalized expression rates of XIAP mRNA (a.u., arbitrary units) in melanoma cells SAN, which were transfected with p65 siRNA or a non-silencing RNA, and irradiated or not with a 4 Gy dose. Vertical bars indicate standard deviations. Values were obtained from three independent experiments. (e) Effect of xIAP downmodulation on Rx-induced apoptosis. Western blot assay of xIAP levels in melanoma cells transfected with NS RNA or xIAP siRNA. At $48 \mathrm{~h}$ after transfection, cells were irradiated with $4 \mathrm{~Gy}$ Rx. Cells were harvested after $6 \mathrm{~h}$ for whole cell lysate preparation. At the same time, a flow cytometric analysis of caspase-3 activation was performed. The graph represents the mean values and standard deviations of active caspase-3 from three different experiments, each performed in triplicate. Apoptosis was measured $48 \mathrm{~h}$ after irradiation by annexin $\mathrm{V}$ binding. A representative result of three independent experiments, performed in triplicate, is shown

exerts transcriptional control on $B E C N-1$ gene expression. ${ }^{22}$ To investigate whether Becn-1, an important component of the autophagic machinery, ${ }^{7-9}$ has a role in the apoptosis inhibition of irradiated cells, we used specific siRNA to downmodulate Becn-1. A western blot assay of whole cell extracts prepared from cells $6 \mathrm{~h}$ after irradiation showed an increase in the level of LC3-II isoform in cells transfected with NS RNA but not those depleted of Becn-1 by specific siRNA (Figure 3d). This finding is in accordance with the concept that Becn- 1 is essential for the activation of autophagy. ${ }^{7-9}$ An analysis of cell death after an additional 40-h incubation showed that the percentage of annexin $\mathrm{V}$-positive cells clearly increased in Becn-1-depleted cells (Figure 3d). This finding was confirmed in two other independent experiments. To investigate the mechanism by which Becn-1 inhibits apoptosis, we investigated the levels of Bax, which is an important component of the permeability transition pore in mitochondrion-dependent apoptosis. ${ }^{23}$ Western blot showed reduced Bax levels in irradiated melanoma cells, which is consistent with its degradation. In Becn-1-silenced cells, Bax levels were higher compared with those in non-silenced cells after irradiation (Figure 3e). Bax localization was investigated by confocal microscopy, in double fluorescence with LC3.
Bax was mostly localized in the nucleus, in basal conditions, and to some extent in the cytosol. After irradiation, nuclear Bax apparently translocated to the cytosol. The presence of colocalization areas in LC3 aggregates (see enlarged detail) suggests a possible inclusion of Bax in autophagic vacuoles (Figure 4a). A semi-quantitative western blot analysis of Bax levels in cells irradiated in the absence or presence of inhibitors of lysosomal proteolysis showed a decrease in Bax levels in irradiated cells, but not when inhibitors of lysosomal proteases were added to the cell culture (Figure 4b). This finding supports the hypothesis of an Rx-induced autophagic degradation of Bax.

Taken together, these findings suggest that Becn-1 expression is controlled by NF- $\kappa \mathrm{B}$, and that autophagy may be an additional mechanism through which such transcriptional activity represses apoptosis.

FKBP51 is expressed in malignant melanoma-initiating cells. Normal stem cells have a high drug efflux capability because of the expression levels of ATP-binding cassette (ABC) transporters, which actively pump drugs out of the cell. The ABC, subfamily $G$, member 2 (ABCG2) is a member of this superfamily of $A B C$ transporter proteins, and it is known 


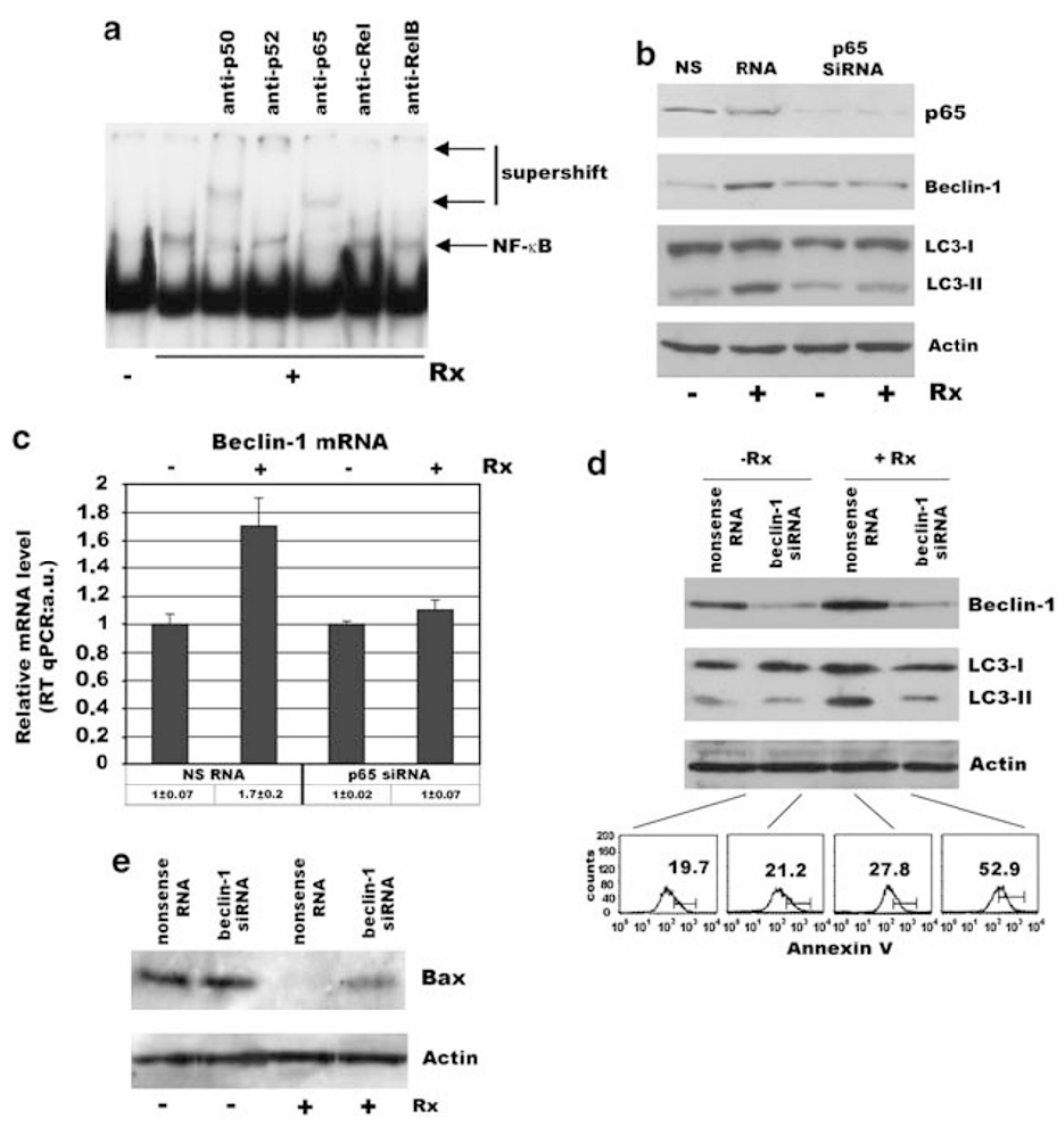

Figure $3 \mathrm{NF}-\kappa \mathrm{B}$ promotes cell survival by enhancing the expression of the autophagic protein beclin-1. (a) Supershift assay of a nuclear extract prepared from SAN melanoma cells $6 \mathrm{~h}$ after a $4 \mathrm{~Gy}$ dose of ionizing radiation (Rx). The extract was incubated with $\left[\gamma^{32} \mathrm{P}\right]$ ATP end-labeled NF- $\kappa \mathrm{B}$ consensus oligonucleotide in the absence or presence of the indicated antibodies against NF- $\kappa$ B and run in a $6 \%$ acrylamide gel electrophoresis. (b) Western blot assay of p65, Becn-1, and LC3-II levels in melanoma cells transfected with non-silencing (NS) RNA or p65 siRNA. At $48 \mathrm{~h}$ after transfection, cells were irradiated with $4 \mathrm{~Gy}$ Rx. Cells were harvested after $6 \mathrm{~h}$ for whole cell lysate preparation. (c) Normalized expression rates of BECN-1 mRNA (a.u., arbitrary units) in melanoma cells SAN, which were transfected with p65 siRNA or a non-silencing RNA, and irradiated or not with a 4 Gy dose. Vertical bars indicate standard deviations. Values were obtained from three independent experiments. (d) The effect of Becn-1 depletion on Rx-induced apoptosis. A representative western blot of Becn-1 levels in melanoma cells transfected with NS RNA or Becn-1 siRNA is shown. At $48 \mathrm{~h}$ after transfection, cells were irradiated with $4 \mathrm{~Gy} \mathrm{Rx}$. A portion of cells was harvested after $6 \mathrm{~h}$ for whole cell lysate preparation. After an additional $42 \mathrm{~h}$, the remaining cells were harvested and apoptosis was measured by annexin $\mathrm{V}$ binding. A representative result of three independent experiments, each performed in triplicate, is shown. (e) The effect of Rx on Bax levels in Becn-1-depleted cells. A representative western blot of Bax levels in melanoma cells transfected with NS RNA or Becn-1 siRNA is shown. At $48 \mathrm{~h}$ after transfection, cells were irradiated with 4 Gy Rx. Cells were harvested after $4 \mathrm{~h}$ for whole cell lysate preparation

to be not only a member of the membrane transporters implicated in multidrug resistance but also a molecular determinant of cancer stem/initiating cells, ${ }^{24}$ including melanoma. ${ }^{25}$ To find whether FKBP51 targeting can overcome radioresistance in such cells with enhanced tumorigenic potential, we investigated whether they expressed this immunophilin. The FKBP51 expression was determined by flow cytometry and immunohistochemistry. After the acquisition of $1 \times 10^{6}$ cells with a flow cytometer, a gate was placed for $\mathrm{ABCG}_{2}{ }^{+}$cells $(0.5 \%$ of total cells), according to ABCG2-PE/SSc parameters (Figure 5a). The expression of FKBP51 in gated cells was then analyzed in the FL-1 channel. The percentage of $\mathrm{FKBP} 51^{+}$events was comparable in $\mathrm{ABCG}_{2}{ }^{+}$and $\mathrm{ABCG} 2^{-}$cells, whereas the mean fluorescence intensity (MFI) was clearly higher in $A B C G 2^{+}$ cells compared with that in $A B C G 2^{-}$cells, suggesting an increased production of FKBP51 in cells with enhanced tumorigenic potential. These data were confirmed in two other different experiments. The expression of FKBP51 in $\mathrm{ABCG}_{2}{ }^{+}$cells was confirmed by immunohistochemistry of cells sorted with the BD FACSAria cell sorting system (BD Biosciences, San Jose, CA USA)(Figure 5b). We then investigated the effect of $\mathrm{Rx}$ on the apoptosis of $\mathrm{ABCG} 2^{+}$ cells. At $48 \mathrm{~h}$ after irradiation, melanoma cells transfected with NS RNA or FKBP51 RNA were harvested and stained with ABCG2-PE and annexin V-FITC. The percentage of annexin $V$-positive events in ABCG2 gated cells clearly indicated a radiosensitizing effect of FKBP51 siRNA on these cells. These data were confirmed in two other independent experiments.

Pretreatment with FKBP51-siRNA promotes apoptosis in irradiated tumor xenografts. We confirmed that the downmodulation of FKBP51 radiosensitized melanoma in vivo. To investigate apoptosis in tumor xenografts, the activation of caspase- 3 was determined by the immunohistochemistry of 
a
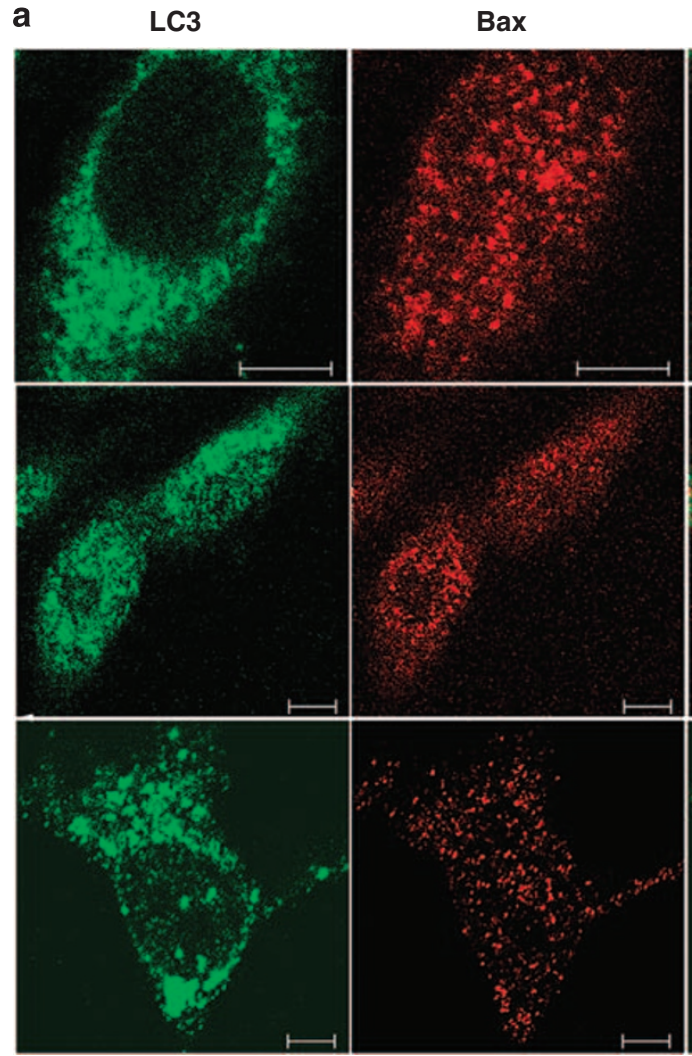

Merge
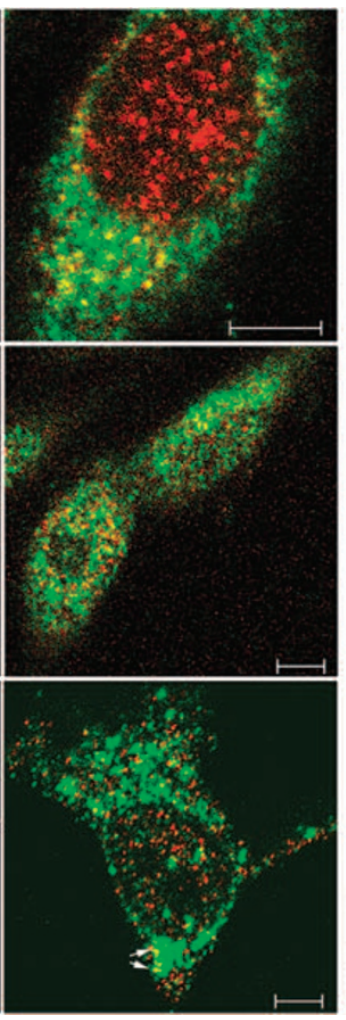

Rx

b

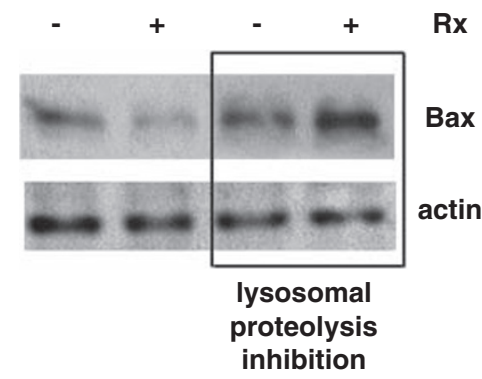

$4 h$

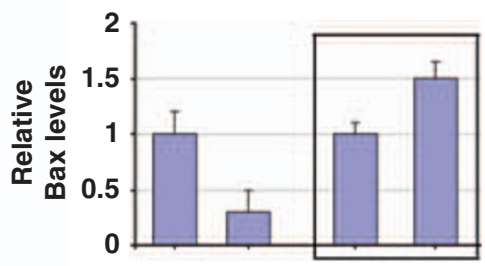

Figure 4 Rx induces Bax delocalization and degradation. (a) Confocal images of cells fixed after $0,4 \mathrm{~h}$, and $6 \mathrm{~h}$ from irradiation with 4 Gy and stained with anti-Bax (red fluorescence) and anti-LC3 (green fluorescence). Enlarged detail of colocalization areas. Bar $5 \mu \mathrm{m}$. The data were confirmed in two further experiments. (b) Western blot of Bax levels in melanoma cells irradiated for $6 \mathrm{~h}$ with $4 \mathrm{~Gy}$, in the absence or presence of $0.25 \mathrm{mM}$ leupeptin $+10 \mu \mathrm{g} / \mathrm{ml}$ pepstatin. Protease inhibitors were added to the culture medium $1 \mathrm{~h}$ before cell harvest. Bax expression levels were quantified by densitometry using NIH Image 1.61 for Macintosh. Integrated optical densities, normalized to actin, were expressed versus baseline level ${ }^{1}$

tumor sections and western blot of tumor lysates. Strong immunoreactivity for cleaved caspase- 3 was found in the tumor tissues from xenografts pretreated with FKBP51 siRNA before irradiation. The apoptosis was more notable in tumors excised $48 \mathrm{~h}$ after irradiation compared with those excised after $24 \mathrm{~h}$ (not shown). Only a few apoptotic cells were detected in both non-irradiated (Figure 6a) and irradiated (Figure 6b) non-silenced tumors in which most of the melanocytes were viable and considerable mitotic activity was present. Few melanocytes showing the morphological signs of apoptosis and caspase-3 immunoreactivity were found in non-irradiated silenced tumors (Figure 6c). In contrast, a prevalence of apoptotic melanocytes with clear caspase-3 immunopositivity was present in irradiated silenced tumors (Figure 6d). Western blot confirmed the prominent activation of caspase- 3 in tumors pretreated with FKBP51 siRNA.

FKBP51 is a marker of malignant melanocytes. Specimens of cutaneous melanoma from 80 patients and 10 samples of normal skin stored in the archive of the Pathology section (Department of Biomorphological and Functional Sciences, University Federico II of Naples, Italy) were examined for FKBP51 expression. In normal skin, no immunopositive melanocytes were found. Table 1 presents the patient profiles relative to the cases studied. In most patients (58/80, 72\%), a low $(+)$ immunopositivity was found in melanocytes during the radial growth phase. Melanocytes in the vertical growth phase displayed a stronger immunopositivity $(++)$ compared with radial melanocytes $\left(P<0.001\right.$, Pearson $\left.\chi^{2}=62.082\right)$. A significant correlation was found between FKBP51 expression and the thickness of the tumor lesion (Spearman's $\rho=0.646$, $P<0.001)$. Moreover, metastatic melanoma was associated with the highest immunoreactivity $(+++)$ (Spearman's $\rho=0.538, P<0.001)$. Figure 7 shows representative immunohistochemical stains for FKBP51 in skin specimens from patients with primitive and metastatic lesions. A definite brown cytoplasmic immunostaining for FKBP51 is visible in tumor, but not normal, melanocytes. The immunoreactivity of the metastatic cutaneous lesion was impressive. In conclusion, our findings unequivocally show that FKBP51 is overexpressed in melanoma lesions of all the patients studied and that FKBP51 expression correlates with malignity of the lesions.

\section{Discussion}

Among cancers, malignant melanoma is one of the most resistant to treatment. ${ }^{1}$ Approximately $80 \%$ of melanomas are diagnosed at a localized stage, and the 5-year survival rate 

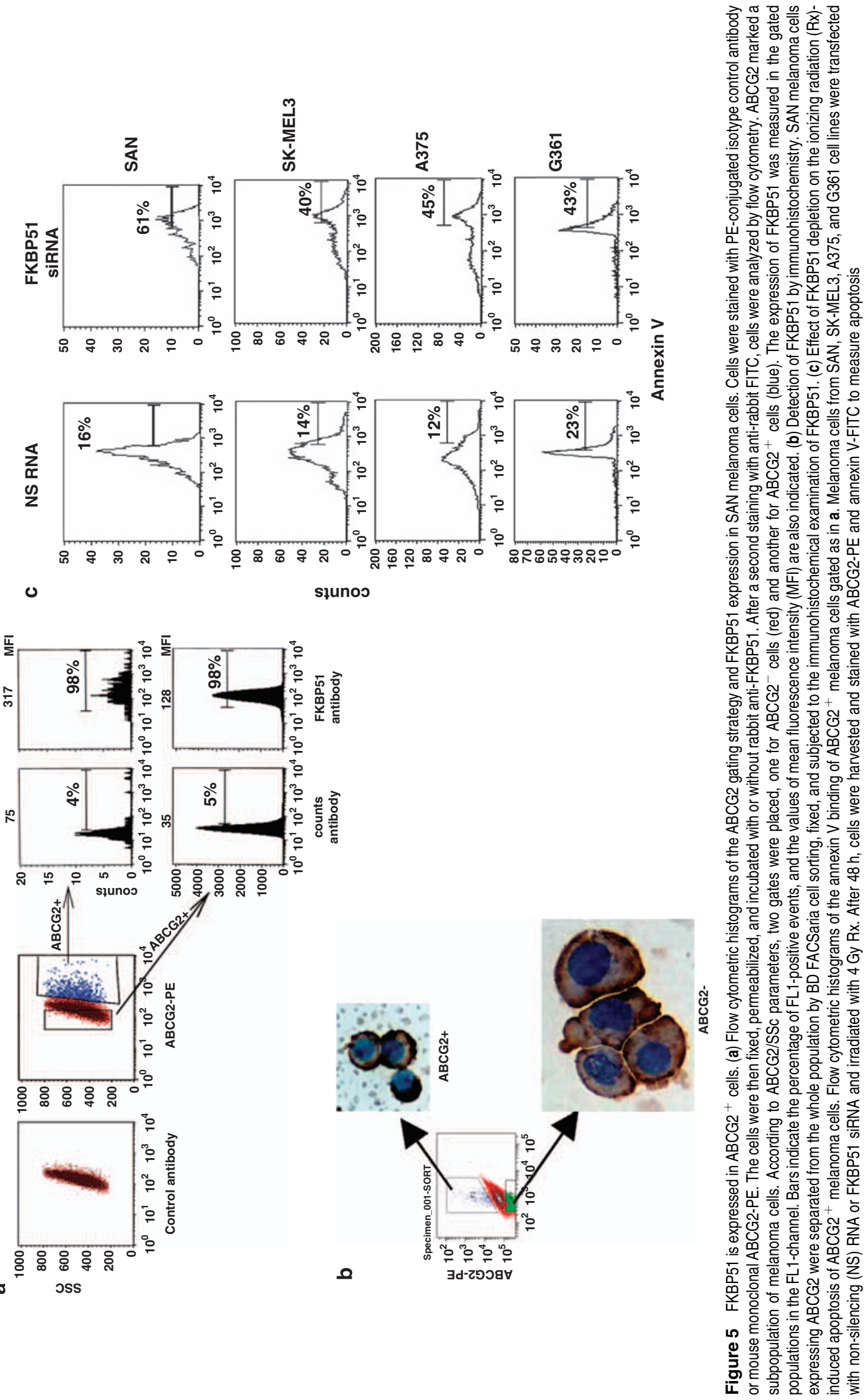
152
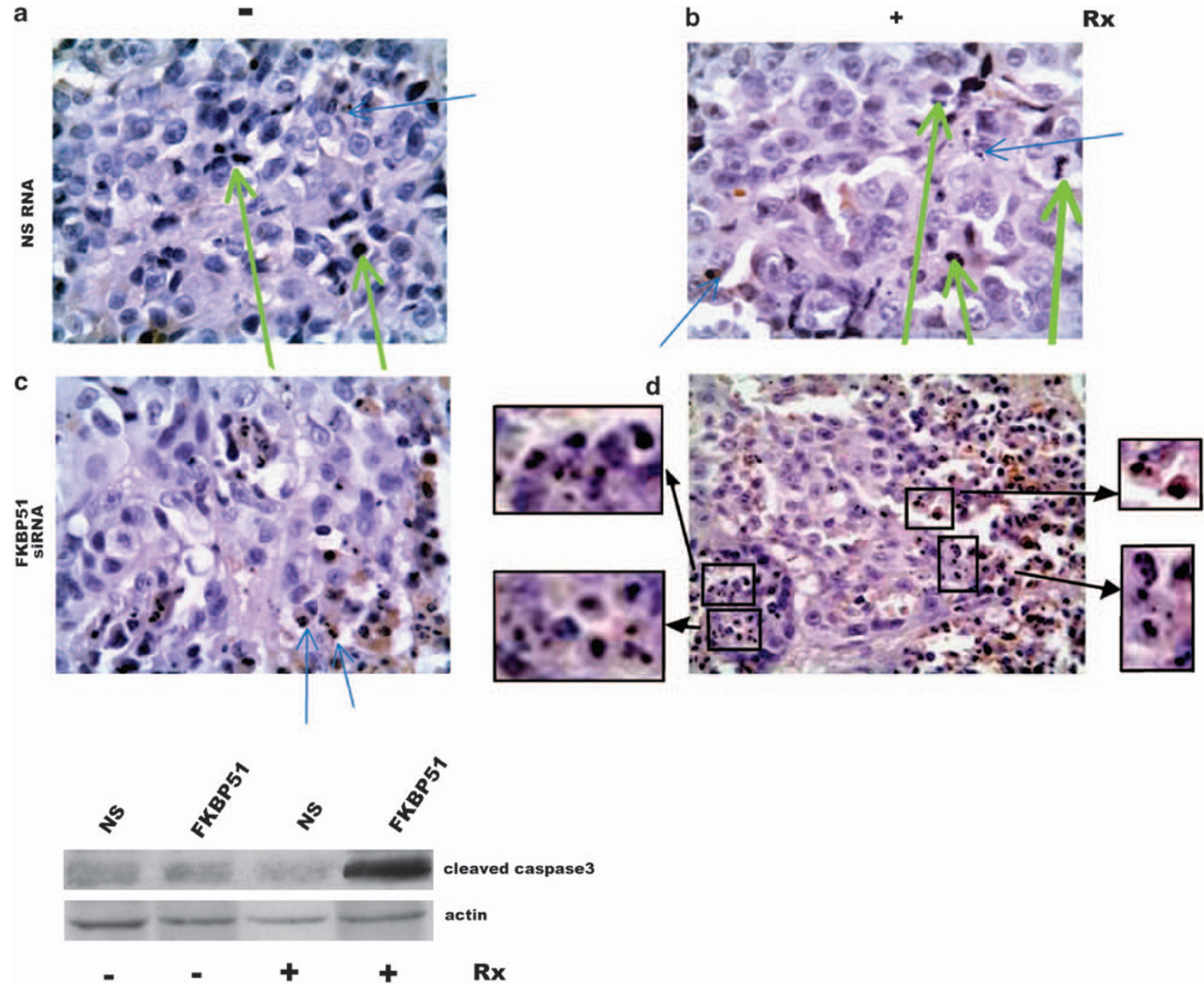

Figure 6 lonizing radiation (Rx)-induced apoptosis in tumor xenografts pretreated with FKBP51 siRNA. Immunohistochemistry and western blot assay of cleaved caspase-3 in tumor sections. Tumors were excised $48 \mathrm{~h}$ after irradiation. For immunohistochemistry, the avidin-biotin complex technique was used. Original magnification, $\times 250(\mathbf{a}, \mathbf{b}, \mathbf{c}) ; \times 150$ (d). The morphology of apoptotic nuclei was indicated by blue arrows; green arrows indicate mitosis. Enlarged details of apoptotic nuclei from panel $\mathbf{d}$ Whole tissue lysates prepared from the same tumors were run in SDS-PAGE for the western blot assay

associated with this form of the disease is roughly $99 \%$. In contrast, the 5-year survival rates for regional and distant stages of the disease are much lower $(65$ and $15 \%$, respectively). ${ }^{1}$ Patients diagnosed with advanced stage melanoma have a very poor prognosis and relatively few treatment options. These patients continue to pose a significant challenge for clinicians. Although many therapeutic regimens for metastatic melanoma have been tested, very few achieve response rates $>25 \%{ }^{26}$ Given the rising incidence of melanoma and the paucity of effective treatments, there is much hope for targeted therapies and promising agents, including those that act on apoptosisregulating molecules. ${ }^{11,27}$ Herein, we showed a novel role for FKBP51 as a marker of melanocyte malignancy and involvement in the protection of melanoma against Rx-induced apoptosis. FKBP51 is a large immunophilin that exerts important biological functions in the cell, among which is the regulation of the steroid hormone response as a component of the steroid hormone receptor complex ${ }^{28}$ and the control of $\mathrm{NF}-\kappa \mathrm{B}$ activation as a cofactor of the IKK $\alpha$ subunit in the IKK complex. ${ }^{29}$ Our data showed that FKBP51 has a relevant role in counteracting apoptotic processes stimulated by $\mathrm{Rx}$. Cellular events were consistent with autophagy, such as an increase in Becn-1 levels and the autophagosome membrane-associated LC3-II isoform, but very few with cell death were observed in irradiated melanoma cells, suggesting that autophagy supports the survival of the tumor cells. Transmission electron microscopy showed an increased number of autophagic vacuoles in irradiated cells. In contrast, typical biochemical markers of apoptosis, such as cleaved caspase- 9 and -3 , phosphatidylserine externalization on the plasma membrane, and hypodiploid DNA in melanoma cell nuclei, were observed in irradiated melanoma cells pretreated with FKBP51 siRNA. In accordance with our earlier findings, ${ }^{10}$ FKBP51 was required for NF- $\kappa$ B activation; in fact, FKBP51 silencing prevented the $\mathrm{Rx}$-induced nuclear translocation of 
Table 1 FKBP51 expression in cutaneous malignant melanoma (CMM) and patients' profiles

\begin{tabular}{|c|c|c|c|c|c|c|c|c|c|c|c|c|c|}
\hline & & & & & & & & & & & & & \\
\hline Case & $\begin{array}{c}\text { Age } \\
\text { (years) }\end{array}$ & Sex & Breslow & FKBP51r & FKBP51v & Follow- & Case & $\begin{array}{c}\text { Age } \\
\text { (years) }\end{array}$ & Sex & Breslow & FKBP51r & FKBP51v & $\begin{array}{l}\text { Follow- } \\
\text { up } \\
\text { (years) }\end{array}$ \\
\hline & & & & & & & 71 & 32 & $\mathrm{M}$ & $2.01-4.00$ & + & ++ & $7 N$ \\
\hline 1 & 58 & $\mathrm{~F}$ & $\leqslant 1.00$ & + & + & 12 & 72 & 38 & $\mathrm{~F}$ & $2.01-4.00$ & + & ++ & $6 \mathrm{~N}$ \\
\hline 2 & 36 & $M$ & $\leqslant 1.00$ & + & + & 12 & 73 & 38 & $\mathrm{M}$ & $2.01-4.00$ & + & ++ & 3 \\
\hline 3 & 67 & $M$ & $\leqslant 1.00$ & + & + & 12 & 74 & 32 & $M$ & $2.01-4.00$ & ++ & +++ & $3 N, M$ \\
\hline 4 & 45 & $\mathrm{~F}$ & $\leqslant 1.00$ & + & + & 12 & 75 & 40 & $\mathrm{M}$ & $2.01-4.00$ & ++ & +++ & 3 \\
\hline 5 & 50 & $\mathrm{~F}$ & $\leqslant 1.00$ & ++ & ++ & 11 & 76 & 46 & $\mathrm{~F}$ & $2.01-4.00$ & ++ & +++ & $3 N$ \\
\hline 6 & 49 & $\mathrm{~F}$ & $\leqslant 1.00$ & + & + & 11 & 77 & 50 & $M$ & $2.01-4.00$ & + & ++ & 2 \\
\hline 7 & 42 & $\mathrm{M}$ & $\leqslant 1.00$ & + & + & 10 & 78 & 24 & $\mathrm{~F}$ & $2.01-4.00$ & + & ++ & 2 \\
\hline 8 & 43 & $\mathrm{~F}$ & $\leqslant 1.00$ & + & + & 9 & 79 & 30 & $\mathrm{M}$ & $2.01-4.00$ & ++ & ++ & 2 \\
\hline 9 & 43 & $M$ & $\leqslant 1.00$ & + & ++ & 9 & 80 & 32 & $\mathrm{~F}$ & $2.01-4.00$ & + & ++ & 2 \\
\hline 10 & 49 & $\mathrm{M}$ & $\leqslant 1.00$ & + & + & 7 & & & & & & & \\
\hline 11 & 40 & $\mathrm{M}$ & $\leqslant 1.00$ & ++ & ++ & 7 & & & & & & & \\
\hline
\end{tabular}

Abbreviations: D, tumor death; FKBP51r, FKBP51 radial growth; FKBP51v, FKBP51 vertical growth; $M$, metastasis; $N$, lymph node; $R$, recidivation.

this transcription factor. Among the apoptosis-regulating proteins under NF- $\kappa$ B control, the IAP family of proteins has been widely involved in the resistance of human cancers to apoptosis induced by both radiotherapy and chemotherapy. ${ }^{30}$ Our data confirmed the important role for xIAP in melanoma radioresistance. A clear enhancement in the expression of xIAP was found after Rx exposure. By using siRNA specific for $x I A P$ silencing, we found caspase-3 activation and cell death after irradiation. Apparently, xIAP was not the only factor contributing to the resistance to apoptosis. Becn-1-silenced cells were also found to be sensitive to Rx. As expected, any increase in the autophagosome-recruited LC3-II isoform was not observed, suggesting the inhibition of autophagy. Reduced Bax levels in irradiated non-silenced cells but not in Becn-1-silenced cells suggest a role for autophagy in Bax degradation. It is noted that Bax is an important mediator of mitochondrion-dependent apoptosis; therefore, its reduced level may represent an additional mechanism for cell death inhibition. ${ }^{23}$ Using siRNA to silence the p65 subunit of the NF- $\kappa \mathrm{B}$ transcription complex, we showed that Becn-1 induction also depended on NF- $\kappa \mathrm{B}$. Taken together, these findings suggest that the activation of $\mathrm{NF}-\kappa \mathrm{B}$ in irradiated melanoma inhibits apoptosis by upregulating the caspase inhibitor XIAP and autophagic protein Becn-1. A scheme of the proposed mechanism is illustrated in Figure 8 . This study identifies a protein that acts upstream of NF- $\kappa \mathrm{B}$, and whose knocking down efficiently overcomes the apoptotic machinery block provoked by this transcription factor, thus permitting Rx-induced killing. The relevant role for FKBP51 in radioresistance has also been documented in vivo. The study of tumor sections from melanoma xenografts implanted in nude mice showed unequivocal and extensive apoptosis provoked by a single dose of FKBP51 siRNA before irradiation.

It is a rapidly emerging concept that the radiocurability of a tumor implicates that the cancer stem or initiating cell is killed. ${ }^{16}$ A cancer stem cell is defined as a cell within a tumor that possesses the capacity to self-renew and generate the heterogeneous cancer cells that comprise the tumor. ${ }^{16}$ Tumor stem or initiating cells have been proposed to exist for melanoma. $^{31}$ The $\mathrm{ABC}$ transporter, $\mathrm{ABCB} 5$, was recently shown to be a marker of cells capable of recapitulating melanomas in xenotransplantation models. ${ }^{32}$ The ABCG2 

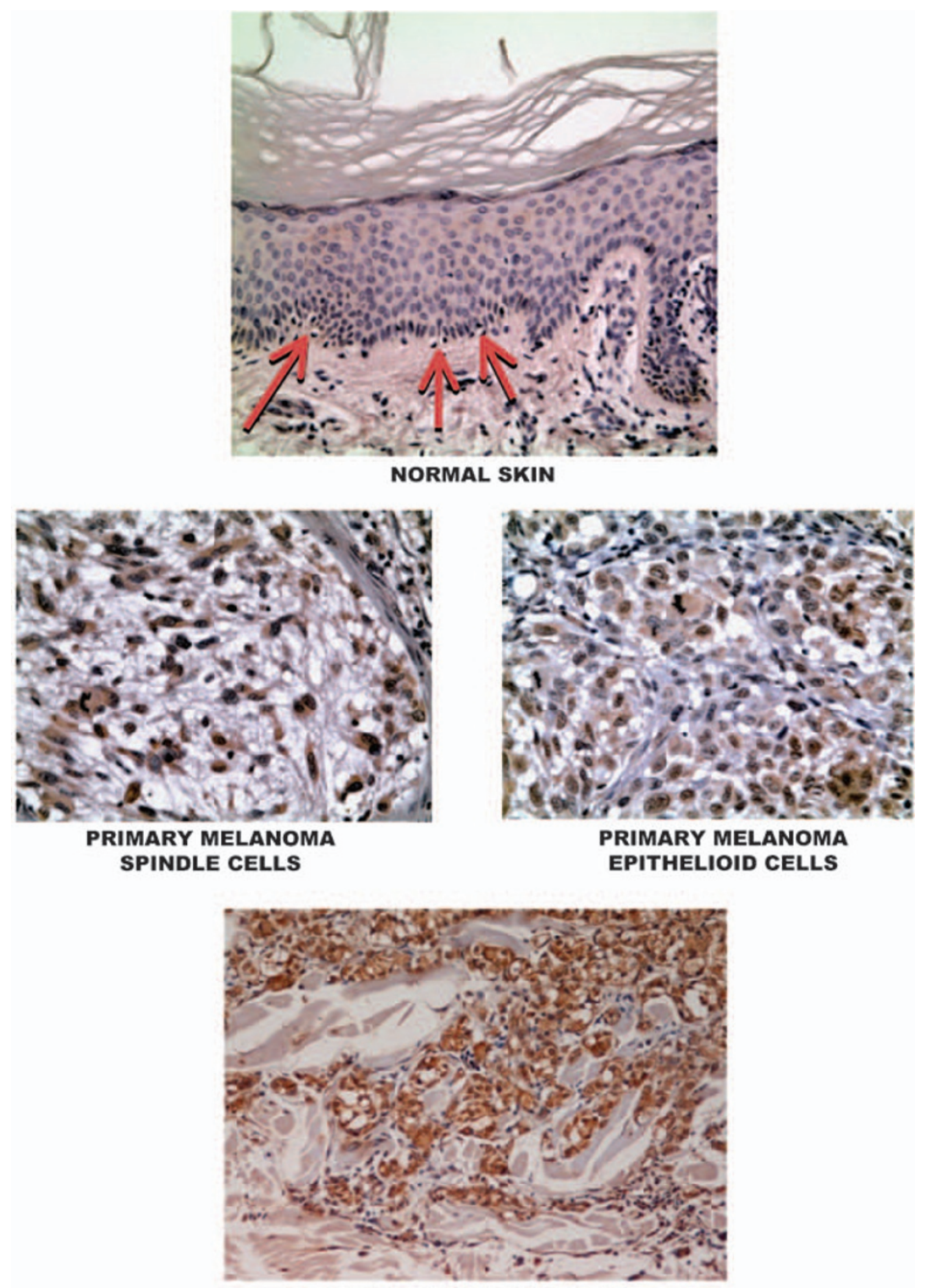

CUTANEOUS METASTASIS

FROM MALIGNANT MELANOMA

Figure 7 FKBP51 expression in normal skin and cutaneous malignant melanoma (CMM). FKBP51 immunochemical staining of normal skin (red arrows indicate melanocytes, original magnification, $\times 200$ ); primary malignant melanoma spindle cells (original magnification, $\times 250$ ); primary malignant melanoma epithelioid cells (magnification, $\times 250$ ); and dermal metastasis from malignant melanoma (original magnification, $\times 150$ ), using the avidin-biotin complex technique

and CD133 proteins have been identified as stemness markers in clinical melanomas. ${ }^{25}$ Using flow cytometric techniques, we showed that $\mathrm{ABCG}_{2}{ }^{+}$melanoma cells contain intracytoplasmic FKBP51 at higher levels than do $\mathrm{ABCG}^{-}$cells, as determined by the MFI values. The presence of FKBP51 was confirmed by an immunohistochemical study of ABCG2-sorted cells. Moreover, a flow cytometry analysis of cells double-stained with ABCG2 and annexin $\mathrm{V}$ allowed us to verify that $\mathrm{ABCG} 2^{+}$cells are also killed by $\mathrm{Rx}$ after pretreatment with siRNA. Taken together, these findings suggest that FKBP51 may be a suitable target for eliminating cancer stem/initiating cells in melanoma.
The translational implication of our findings was reinforced by data obtained from a study on 80 melanoma patients. The protein expression was investigated in CMM both primitive and metastatic. The relevant data from this analysis are that FKBP51 (i) was expressed in all CMMs analyzed but not in normal skin; (ii) expression was higher in melanocytes during the vertical growth phase compared with the radial growth phase; (iii) expression correlated with the thickness of the tumor lesion; (iv) expression was maximal in metastatic melanoma. In conclusion, we show that FKBP51, a protein with important biological roles in normal cells, ${ }^{28,29,33}$ acquires a pro-oncogenic potential when its expression is deregulated, 

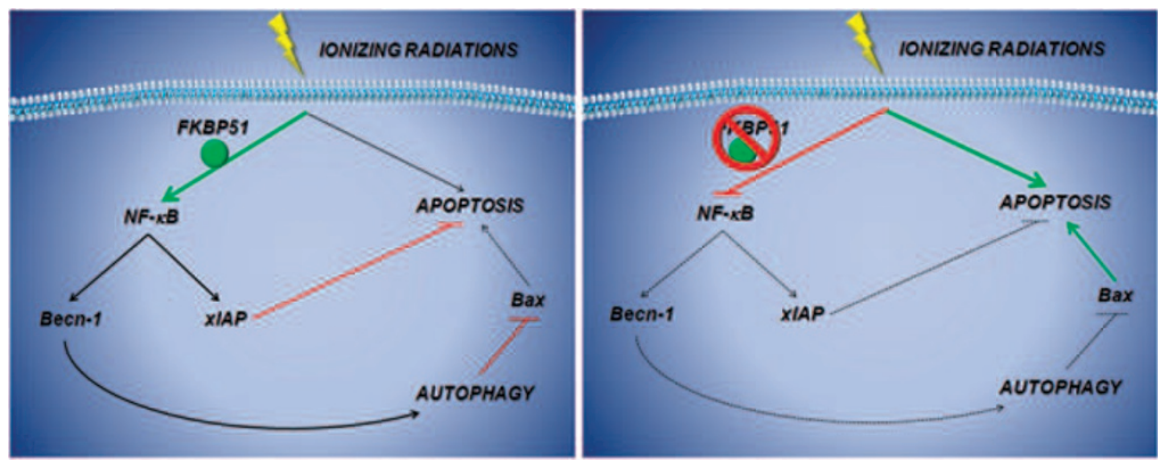

Figure 8 Schematic representation of the proposed mechanism for the FKBP51 suppression of ionizing radiation (Rx)-induced apoptosis. Rx triggers both the apoptotic and NF- $\kappa$ B pathways. FKBP51 is required for the activation of NF- $\kappa$ B, which in turn inhibits apoptosis by stimulating xIAP and promoting authophagy-mediated Bax degradation. In FKBP51-silenced cells, the lack of NF- $\kappa \mathrm{B}$ induction permits the activation of apoptotic machinery, leading to cellular suicide

which is what occurs in melanoma. Such deregulation might sustain survival networks that protect the melanoma against killing. Our finding, that FKBP51 controls Rx-induced apoptosis in melanoma and correlates with malignity of the lesions, provides a novel potential target for signaling therapies of advanced disease and opens the door to the development of diagnostic and prognostic tools for FKBP51 expression profile, which can provide important insights into melanoma biology and progression.

\section{Materials and Methods}

Cell culture. The melanoma cell line $\mathrm{SAN}^{10,34}$ was established from a patient's tumor lymphonodal metastasis and was provided by Dr. Gabriella Zupi (Experimental Preclinic Laboratory, Regina Elena Institute for Cancer Research, Roma, Italy). Cells were cultured in RPMI (Roswell Park Memorial Institute) 1640 medium (Lonza, Braine-l'Alleud, Belgium) supplemented with $10 \%$ heat-inactivated fetal bovine serum (FBS) (Lonza), $200 \mathrm{mM}$ glutamine (Lonza), and $100 \mathrm{U} / \mathrm{ml}$ penicillin-streptomycin (Lonza) at $37^{\circ} \mathrm{C}$ in a $5 \% \mathrm{CO}_{2}$ humidified atmosphere. The melanoma cell lines G361 and SK-MEL- $3^{35}$ (derived from a primary tumor and a lymphonodal metastasis, respectively) were cultured in McCoy's modified medium (Sigma Aldrich, Saint Louis, MO, USA) supplemented with $10 \%$ heat-inactivated FBS, $200 \mathrm{mM}$ glutamine and $100 \mathrm{U} / \mathrm{ml}$ penicillin-streptomycin at $37^{\circ} \mathrm{C}$ in a $5 \% \mathrm{CO}_{2}$ humidified atmosphere. The melanoma cell line $\mathrm{A} 375,{ }^{36}$ derived from a metastatic tumor, was cultured in Dulbecco's Modified Eagle's Medium (Lonza) supplemented with $15 \%$ heat-inactivated FBS, $200 \mathrm{mM}$ glutamine, and $100 \mathrm{U} / \mathrm{ml}$ penicillinstreptomycin at $37^{\circ} \mathrm{C}$ in a $5 \% \mathrm{CO}_{2}$ humidified atmosphere. G361, SK-MEL-3, and A375 were kindly provided by Dr. Rosella Di Noto (CEINGE, Naples, Italy).

Cell transfection. At $24 \mathrm{~h}$ before transfection, cells were seeded into six-well plates at a concentration of $2 \times 10^{5} \mathrm{celll} / \mathrm{ml}$ to obtain $30-60 \%$ confluence at the time of transfection. Then, the cells were transfected with specific short interfering oligoribonucleotide (siRNA) or with a non-silencing oligoribonucleotide (NS RNA) as control, at a final concentration of $50 \mathrm{nM}$ using Metafectene (Biontex, Munich, Germany) according to the manufacturer's recommendations. NS RNAs and siRNAs corresponding to human CDNA sequences for FKBP51, FKBP12, RelA, $\mathrm{XIAP}$, and Becn-1 were purchased from Qiagen (Germantown, Philadelphia, PA, USA). The siRNA sequences were:

5'-ACCUAAUGCUGAGCUdAU-3' for FKBP51;

5'-GCTTGAAGATGGAAAGAAA-3' for FKBP12;

$5^{\prime}$ AAGATCAATGGCTACACAGGA- $3^{\prime}$ for RelA (p65);

5'-AAGTGCTTTCACTGTGGAGGA-3' for Birc4 (XIAP);

$5^{\prime}$-AGGGTCTAAGACGTCCAACAA - $3^{\prime}$ for Becn-1.

At $48 \mathrm{~h}$ after transfection, cells were irradiated with a $6 \mathrm{MV}$ X-ray of a linear accelerator (Primus, Siemens, München, Deutschland) and processed according to the different experimental procedures.
Clonogenic assay. This assay was performed as described earlier. ${ }^{37}$ Briefly, melanoma cells, not transfected and transfected with FKBP51 siRNA or with NS RNA, were irradiated at Rx doses between 1 and $8 \mathrm{~Gy}$, harvested and plated in triplicate at a density of $500 \mathrm{cells} / \mathrm{plate}$. After 10 days, the formed colonies were stained with crystal violet and counted. The mean colony count was calculated for each treatment (both Rx dose and type of cell transfection). The number of colonies in the irradiated dishes was divided by the number of colonies in the non-irradiated dishes and expressed as a percentage. The graph of percent survival ( $y$ axis) against $\mathrm{Rx}$ dose ( $x$ axis) was performed in semilogarithmic scale.

Cell lysates and western blot assay. Whole cell lysates were prepared by homogenization in modified RIPA buffer ( $150 \mathrm{mM}$ sodium chloride, $50 \mathrm{mM}$ Tris- $\mathrm{HCl}, \mathrm{pH}$ 7.4, $1 \mathrm{mM}$ ethylenediamine tetraacetic acid (EDTA), $1 \mathrm{mM}$ phenylmethylsulfonyl fluorite (PMSF), 1\% Triton X-100, 1\% sodium deoxycholic acid, $0.1 \%$ sodium dodecylsulfate (SDS), $5 \mu \mathrm{g} / \mathrm{ml}$ aprotinin, and $5 \mu \mathrm{g} / \mathrm{ml}$ leupeptin). For $\mathrm{I}_{\kappa} \mathrm{B} \alpha$ and $\mathrm{I}_{\kappa} \mathrm{B} \beta$ detection, cytosolic extracts were obtained from $1 \times 10^{6}$ cells resuspended in $50 \mu \mathrm{l}$ of lysing buffer (10 mM HEPES, pH 7.9, $1 \mathrm{mM}$ EDTA, $60 \mathrm{mM} \mathrm{KCl}, 1 \mathrm{mM}$ dithiothreitol, $1 \mathrm{mM}$ PMSF, $50 \mu \mathrm{g} / \mathrm{ml}$ antipain, $40 \mu \mathrm{g} / \mathrm{ml}$ bestatin, $20 \mu \mathrm{g} / \mathrm{ml}$ chymostatin, and $0.2 \% \mathrm{v} / \mathrm{v}$ Nonidet P-40) for $15 \mathrm{~min}$ in ice. Cell debris was removed by centrifugation. Protein concentration was determined using the Bradford protein assay. Cell lysates were equalized for total protein, run in 10-14\% SDS in polyacrylamide gel electrophoresis (PAGE) and transferred onto a methanol-activated polyvinylidene difluoride membrane (Millipore, Tokyo, Japan), which was incubated with the primary antibody. The goat polyclonal antibodies against FKBP51 (F-13), FKBP12 (N-19), and Actin (I-19) (Santa Cruz Biotechnology, Santa Cruz, CA, USA); the rabbit polyclonal antibodies against Becn-1 (H-300), I $\kappa$ B $\alpha$ (C-21), I $\kappa B \beta(C-20)$ (Santa Cruz Biotechnology), LC3 (Novus Biologicals, Littleton, CO, USA), caspase-7 (C7724, Sigma, Saint Louis, MO, USA), and cleaved caspase-3 (Asp175) (Cell Signaling, Danvers, MA, USA) were used diluted 1:500. The mouse monoclonal antibodies against caspase-3 (specific for both pro-caspase and cleaved caspase-3) (Sigma Aldrich), XIAP (Stressgene, San Diego, CA, USA) and Bax (B-9, Santa Cruz Biotechnology) were used diluted 1: 1000. The blots were developed with an electrochemiluminescence system (ECL) (GE Healthcare-Amersham, Buckinghamshire, UK).

Transmission electron microscopy. Melanoma cells, irradiated or nonirradiated, were plated on 60-mm dishes. At 30-50\% confluence, the cells were fixed with $2 \%$ glutaraldehyde in $0.2 \mathrm{M} \mathrm{Hepes,} \mathrm{pH} 7.4$, at room temperature for $30 \mathrm{~min}$. The cells were scraped and pelleted, and the fixation was continued for $2 \mathrm{~h}$. The cells were then dehydrated in ethanol and embedded in epoxy resin. Thin sections were cut and stained with uranyl acetate and lead citrate, and examined under a Jeol JEM1200 EX2 Transmission Electron Microscope (Jeol, Tokyo, Japan).

Nuclear extracts, EMSA, and oligonucleotides. Cell nuclear extracts were prepared from $1 \times 10^{6}$ cells by homogenization of the cell pellet in two volumes of $10 \mathrm{mM}$ HEPES, pH 7.9, $10 \mathrm{mM} \mathrm{KCl}, 1.5 \mathrm{mM} \mathrm{MgCl}$, $200 \mathrm{mM}$ EDTA, $0.5 \mathrm{mM}$ DTT, $0.5 \mathrm{mM}$ PMSF, and $10 \%$ glycerol $(\mathrm{v} / \mathrm{v})$. Nuclei were centrifuged at $1000 \times g$ for $5 \mathrm{~min}$, washed, and resuspended in two volumes of the abovespecified solution. $\mathrm{KCl}(3 \mathrm{M})$ was added until the concentration reached $0.39 \mathrm{M}$. Nuclei were extracted at $4^{\circ} \mathrm{C}$ for $1 \mathrm{~h}$ and centrifuged at $10000 \times g$ for $30 \mathrm{~min}$. The 
supernatants were clarified by centrifugation and stored at $-80^{\circ} \mathrm{C}$. Protein concentrations were determined using the Bradford method. The NF- $\kappa B$ consensus $5^{\prime}$-CAACGGCAGGGGAATCTCCCTCTCCTT-3' oligonucleotide ${ }^{3}$ was end-labeled with $\left[\gamma^{32} \mathrm{P}\right]$ ATP using a polynucleotide kinase (Roche, Basel, Switzerland). Endlabeled DNA fragments were incubated at room temperature for 20 min with $5 \mu \mathrm{g}$ of nuclear protein, in the presence of $1 \mu \mathrm{g}$ poly $(\mathrm{dl}-\mathrm{dC})$, in $20 \mu \mathrm{l}$ of a buffer consisting of $10 \mathrm{mM}$ Tris- $\mathrm{HCl}, \mathrm{pH} 7.5,50 \mathrm{mM} \mathrm{NaCl}, 1 \mathrm{mM}$ EDTA, $1 \mathrm{mM} \mathrm{DTT}$, and $5 \%$ glycerol (v/ v). In supershifting experiments, rabbit antibodies against p105/p50 (N-19), p65 (F-6), chel (N), RelB (C-19) (Santa Cruz Biotechnology), and against p52 (kindly provided by Professor Shao-Cong Sun, Department of Microbiology and Immunology, Pennsylvania State University College of Medicine, Hershey, PA, USA) were added to the incubation mixture. In competition assays, a $50 \times$ molar excess of NF- $\kappa$ B or NFAT cold oligo was added to the incubation mixture. ProteinDNA complexes were separated from the free probe on a $6 \%$ polyacrylamide $(\mathrm{w} / \mathrm{v})$ gel run in $0.25 \times$ Tris borate buffer at $200 \mathrm{mV}$ for $3 \mathrm{~h}$ at room temperature. The gels were dried and exposed to X-ray film (Fuji film, L.E.P., Naples, Italy).

Analysis of apoptosis. Caspase- 3 and -9 activity was determined using the Carboxyfluorescein Fluorochrome Inhibitor of Caspases Assay (FLICA) Kits (B-Bridge International, San Jose, USA,) according to the instructions of the manufacturer. Cells are permeable to the fluorochrome inhibitor that binds covalently to the activated caspase, thereby inhibiting enzymatic activity. Briefly, $4 \mathrm{~h}$ after exposure to a $4 \mathrm{~Gy} \mathrm{Rx}$ dose, the cells were harvested and resuspended in $300 \mu \mathrm{l}$ PBS containing FLICA reagent, for $1 \mathrm{~h}$ at $37^{\circ} \mathrm{C}$ in a $5 \% \mathrm{CO}_{2}$ atmosphere, in the dark. During the incubation, cells were gently resuspended twice to ensure an optimal distribution of the FLICA reagent among all cells. Then, the cells were washed twice in wash buffer by centrifugation at $400 \times g$ for $5 \mathrm{~min}$, resuspended in $300-400 \mu \mathrm{l}$ of PBS, and analyzed by flow cytometry. The green fluorescent signal was a direct measure of the number of active caspase enzymes. Phosphatidylserine externalization was investigated by annexin $\mathrm{V}$ staining. Briefly, $1 \times 10^{5}$ cells were harvested $48 \mathrm{~h}$ after Rx exposure ( $4 \mathrm{~Gy}$ ) and resuspended in $100 \mu \mathrm{l}$ of binding buffer ( $10 \mathrm{mM}$ Hepes/ $\mathrm{NaOH}$ pH 7.5, $140 \mathrm{mM} \mathrm{NaCl}$, and $2.5 \mathrm{mM} \mathrm{CaCl}_{2}$ ) containing $5 \mu$ l of annexin V-FITC (Pharmingen/Becton Dickinson, San Diego, CA, USA) for $15 \mathrm{~min}$ at room temperature in the dark. Then, $400 \mu \mathrm{l}$ of the same buffer was added to each sample and the cells were analyzed with a Becton Dickinson FACScan flow cytometer (Becton Dickinson). The peptide caspase-3 inhibitor Z-Asp-Glu-Val-Asp fluoromethyl ketone (Z-DEVD-fmk) was provided by Sigma Aldrich.

Analysis of DNA content by propidium iodide incorporation was performed in permeabilized cells by flow cytometry. Cells $\left(2 \times 10^{4}\right)$ were harvested $72 \mathrm{~h}$ after $\mathrm{Rx}$ exposure (4 Gy), washed in PBS, and resuspended in $500 \mu$ l of a solution containing $0.1 \%$ sodium citrate $\mathrm{w} / \mathrm{v}, 0.1 \%$ Triton $\mathrm{X}-100 \mathrm{v} / \mathrm{v}$, and $50 \mu \mathrm{g} / \mathrm{ml}$ propidium iodide (Sigma Chemical $\mathrm{Co}$, Gallarate, Italy). After incubation at $4^{\circ} \mathrm{C}$ for $30 \mathrm{~min}$ in the dark, cell nuclei were analyzed with an FACScan flow cytometer. Cellular debris was excluded from the analysis by raising the forward scatter threshold, and the DNA content of the nuclei was registered on a logarithmic scale. The percentage of the elements in the hypodiploid region was calculated.

Real-time PCR. Total RNA was isolated by Trizol (Invitrogen, Carlsbad, CA, USA) from cells harvested $6 \mathrm{~h}$ after Rx, according to the instructions of the manufacturer. A total of $1 \mu \mathrm{g}$ of each RNA was used for CDNA synthesis with Moloney Murine Leukemia Virus Reverse Transcriptase (Invitrogen). Gene expression was quantified by real-time PCR using the iQSYBR Green Supermix (Biorad, Hercules, CA, USA) and specific real-time-validated QuantiTect primers for Bax, Becn-1, and XIAP (Qiagen) and specific primers for $\beta$-actin: Fw $5^{\prime}$-CGACA GGATGCAGAAGGAGA-3', Rev 5'-CGTCATACTCCTGCTTGCTTGCTG-3'.

Confocal microscopy. Cells were fixed in $4 \%$ paraformaldehyde in PBS for $20 \mathrm{~min}$, washed twice for 5 min each time, with $50 \mathrm{mM} \mathrm{NH}_{4} \mathrm{Cl}$ in PBS permeabilized for $5 \mathrm{~min}$ in $0.1 \%$ Triton $\mathrm{X}-100$ in PBS. The cwere then blocked in $1 \%$ bovine serum albumin (BSA) in PBS for $1 \mathrm{~h}$ and washed twice in PBS. Mouse monoclonal anti-Bax (Santa Cruz Biotechnology) and rabbit polyclonal LC3 (Novus Biologicals), diluted $1: 40$ in PBS $0.5 \%$ BSA for $1 \mathrm{~h}$ in a humidified atmosphere, served as the primary antibody. The cells were then extensively washed in PBS before staining with secondary goat anti-mouse Alexa Fluor 546 and anti-rabbit Alexa Fluor 488 (Molecular Probe, Invitrogen Corporation, Carlsbad, CA, USA). Nuclei were counterstained with Hoechst $33258(0.5 \mu \mathrm{g} / \mathrm{ml}$ in PBS) (Sigma Aldrich) for $10 \mathrm{~min}$. Finally, the cells were washed in PBS and mounted on glass slides with PBS containing $50 \%$ glycerol.
The analysis of immunofluorescence was performed with a confocal laser scanner microscopy Zeiss 510 LSM (Carl Zeiss Microimaging GmbH, München, Germany), equipped with Argon ionic laser (Carl Zeiss Microimaging $\mathrm{GmbH}$, München, Germany) whose / was set up to $488 \mathrm{~nm}$, a HeNe laser whose / was set up to $546 \mathrm{~nm}$, and an immersion oil objective, $63 \times / 1.4$. Emission of fluorescence was shown by a BP $505-530$ band pass filter for Alexa- 488 and 560 long pass for Alexa-546. Images for the double-staining immunofluorescence were acquired by sequential scanning to eliminate the cross talk of chromophores in the green and red channels and then saved in TIFF format to prevent the loss of information. They had been acquired with a resolution of $1024 \times 1024$ pixel with the confocal pinhole set to one Airey unit.

Cell sorting and immunostaining of $\mathbf{A B C G 2}^{+}$cells. SAN melanoma cells were harvested, centrifuged for $5 \mathrm{~min}$ at $400 \times g$, and incubated with a monoclonal antibody against human ABCG2-pycoerythrin (PE) conjugated (R\&D Systems, Minneapolis, MN, USA). After incubation at $4^{\circ} \mathrm{C}$ for $30 \mathrm{~min}$ in the dark, cells were fixed with $2 \%$ paraformaldehyde in PBS for $1 \mathrm{~h}$ and permeabilized with $0.1 \%$ Triton X-100 and $0.1 \%$ sodium citrate in PBS for $3 \mathrm{~min}$ in ice. Afterward, intracellular indirect immunostaining was performed with anti-FKBP51 (H-100) (Santa Cruz Biotechnology) and a secondary fluorescein isothiocyanate (FITC)conjugated antibody. Expression of FKBP51 in both $\mathrm{ABCG}^{+}$and $\mathrm{ABCG}{ }^{-}$cells was analyzed in flow cytometry by using the ABCG2-PE/SSc gating strategy. For the immunohistochemistry of $\mathrm{ABCG}^{+}{ }^{+}$cells, these were sorted from the whole cells of the melanoma cell line SAN with a BD FACSAria (BD Biosciences). The ABCG2 ${ }^{+}$population was $>77 \%$ in purified cells. The sorted cells were immediately fixed with $2 \%$ paraformaldehyde in PBS. Then, the cells were deposited on a slide (Cytoslide Shandon, Waltham, MA, USA) by spinning in a cytocentrifuge (Cytospin 3, Shandon) at 600 r.p.m. for $5 \mathrm{~min}$, and subjected to FKBP51 immunohistochemical staining.

Immunohistochemistry. Serial sections of $4-\mu \mathrm{m}$ thickness from routinely formalin-fixed, paraffin-embedded blocks were cut for each case of CMM and normal skin, and mounted on poly-l-lysine-coated glass slides, as described earlier. ${ }^{36}$ Briefly, deparaffinized sections were boiled thrice for $3 \mathrm{~min}$ in a $1 \mathrm{mM}$ sodium citrate buffer ( $\mathrm{pH} 6.0)$, as an antigen retrieval method. To prevent a nonspecific binding of the antibody, sections were preincubated with a non-immune mouse serum (1:20; Dakopatts, Hamburg, Germany) diluted in PBS-BSA (1\%) for $25 \mathrm{~min}$ at room temperature. After quenching of endogenous peroxidases with $0.3 \%$ hydrogen peroxide in methanol, followed by two rinses with Tris- $\mathrm{HCl}$ buffer, the sections were incubated with the anti-FKBP51 primary antibody (F-13) (Santa Cruz Biotechnology) diluted $1: 50$ overnight at $4{ }^{\circ} \mathrm{C}$. The standard streptavidin-biotinperoxidase complex technique, using sequential $20 \mathrm{~min}$ incubation with biotinylated linking antibody and peroxidase-labeled streptavidin (labeled streptavidin-biotin complex kit horseradish peroxidase, DAKO, Carpinteria, CA, USA), was performed. 3,3V-diaminobenzidine (3-3V diaminobenzidine tetrachloride; Vector Laboratories, Burlingame, CA) was used as a substrate chromogen solution for the development of the peroxidase activity. Hematoxylin was used for nuclear counterstaining; then, the sections were mounted and coverslipped with a synthetic mounting medium (Entellan, Merck, Darmstadt, Germany). As control, an antibody with irrelevant specificity, but with the same isotype as the primary antibody, was used in each staining run. Only cells with a definite brown cytoplasmatic immunostaining were judged as positive for FKBP51 antibody. The immunohistochemical expression of FKBP51 in CMM was evaluated semiquantitatively as the percentage of positive tumor cells among the total melanoma cells present in at least 10 representative fields and scored according to an arbitrary scale (Staibano et al. ${ }^{38}$ ) as follows: 0 (no immunopositive cells); $+(<5 \%$ of positive cells $) ;++(>5 \%$ and $<25 \%$ of positive cells); $+++(>25 \%$ of positive cells $)$.

Animal studies. SAN melanoma cells, $3 \times 10^{6}$ in a volume of $100 \mu \mathrm{l}$ PBS, were injected s.c. into one flank of 24 6-week-old athymic nu/nu mice (Charles River Laboratory, Wilmington, MA, USA). Mice were maintained under specific pathogenfree conditions in the Laboratory Animal Facility of the National Cancer Institute, G Pascale Foundation, Naples, Italy. All studies were conducted in accordance with Italian regulations for experimentations on animals. Mice were observed daily for the visual appearance of tumors at the injection sites. Tumor diameters were measured using calipers and calculated as the mean value between the shortest and the longest diameters. When tumors reached $\sim 10 \mathrm{~mm}$ in mean diameter, 3-4 weeks post-injection of cells, 12 mice were subjected to a single intratumor injection of FKBP51 siRNA and 12 to an injection of NS RNA. After $48 \mathrm{~h}, 12$ mice (six treated with 
FKBP51 siRNA and six with NS RNA) were subjected to tumor irradiation. A total of six irradiated animals (three injected with NS RNA and three with FKBP51 siRNA) and six non-irradiated animals (three injected with NS RNA and three with FKBP51 siRNA) were killed $24 \mathrm{~h}$ after irradiation. The remaining 12 animals were killed a day later. Each tumor was divided into two parts: one portion was formalin-fixed and paraffinembedded for immunohistochemistry and the other was processed for the preparation of whole cell lysates. For immunohistochemical assays, $5-\mu \mathrm{m}$-thick paraffin-embedded sections were incubated with Tris-buffered saline (TBS)/BSA for $10 \mathrm{~min}$ to reduce unspecific staining. Tissue sections were then exposed to rabbit polyclonal antibody against cleaved caspase-3 (Asp175) (Cell Signaling) or isotype-matched control antibody for $1 \mathrm{~h}$. After two washes in TBS, sections were exposed to anti-rabbit biotinylated antibody, washed again, and incubated with peroxidase-labeled streptavidin. 3,3V-diaminobenzidine was used as a substrate chromogen solution for the development of peroxidase activity. Counterstaining of tumor sections was performed using aqueous hematoxylin. Lysates of excised tumors were prepared by homogenization in modified RIPA buffer. Homogenization was conducted in a Dounce Homogenizer, before incubation for $1 \mathrm{~h}$ at $4^{\circ} \mathrm{C}$. Preparations were subsequently clarified by centrifugation at $14000 \times g$ for $30 \mathrm{~min}$ at $4^{\circ} \mathrm{C}$. The protein content of the supernatants was determined using the Bradford method. Samples were equalized for total protein and run in SDS-PAGE electrophoresis. Western blot filter was incubated with the rabbit polyclonal antibody for cleaved caspase-3 (Asp175) (Cell Signaling).

Statistical analysis. The results reported are the mean and standard deviation of independent experiments. The statistical significance of differences between means was estimated using Student's $t$-test. The $\chi^{2}$-test was used to assess the difference between categorical variables. The Spearman's rank correlation coefficient was used for non-parametric data. Values of $P \leqslant 0.05$ were considered statistically significant. The statistical analysis was performed using the SPSS statistical package (SPSS Inc., Chicago, IL, USA).

Acknowledgements. The authors are grateful to Professor Eric Baehrecke (University of Massachusetts Medical School, Worcester, MA, USA) for advice and helpful discussion, Dr. Raffaele Liuzzi (Institute of Biostructure and Bio-Imaging National Research Council, Naples, Italy) for contribution to statistical analysis, Professor Luigi Del Vecchio (CEINGE, Naples, Italy) for cell sorting, the Electron Microscopy Unit at the Institute of Biotechnology, University of Helsinki for access to equipment and technical help. It is stated that no conflict of interest exists. The work is supported by funds from the Italian Association for Cancer Research (AIRC) and MIUR (Ministero Istruzione, Università e Ricerca).

1. Norris LB, Beam S. Multidisciplinary perspectives on melanoma treatment. Updates from the 44th Annual Meeting of the American Society of Clinical Oncology, The Oncology Nurse 2008; 1: 1-7.

2. Dewey WC, Ling CC, Meyn RE. Radiation-induced apoptosis: relevance to radiotherapy. Int J Radiat Oncol Biol Phys 1995; 33: 781-796.

3. Wallace SS. DNA damages processed by base excision repair: biological consequences Int J Radiat Biol 1994; 66: 579-589.

4. Hengartner MO. The biochemistry of apoptosis. Nature 2000; 407: 770-776.

5. Elliott A, Reiners Jr JJ. Suppression of autophagy enhances the cytotoxicity of the DNA damaging aromatic amine p-anilinoaniline. Toxicol Appl Pharmacol 2008; 232: 169-179.

6. Ogata M, Hino S, Saito A, Morikawa K, Kondo S, Kanemoto S et al. Autophagy is activated for cell survival after endoplasmic reticulum stress. Mol Cell Biol 2006; 26: 9220-9231.

7. Eskelinen EL. New insights into the mechanisms of macroautophagy in mammalian cells. Int Rev Cell Mol Biol 2008; 266: 207-247. Review.

8. Baehrecke EH. Autophagy: dual roles in life and death? Nat Rev Mol Cell Biol 2005; 6 : 505-510. Review.

9. Mathew R, Karantza-Wadsworth V, White E. Role of autophagy in cancer. Nat Rev Cancer 2007; 7: 961-967.

10. Romano MF, Avellino R, Petrella A, Bisogni R, Romano S, Venuta S. Rapamycin inhibits doxorubicin-induced NF-kappaB/Rel nuclear activity and enhances the apoptosis of melanoma cells. Eur J Cancer 2004; 40: 2829-2836.

11. Johnson GE, Ivanov VN, Hei TK. Radiosensitization of melanoma cells through combined inhibition of protein regulators of cell survival. Apoptosis 2008; 13: 790-802.

12. Munshi A, Kurland JF, Nishikaw T, Chiao PJ, Andreeff M et al. Inhibition of constitutively activated nuclear factor-kappaB radiosensitizes human melanoma cells. Mol Cancer Ther 2004; 3: 985-992.
13. Ghosh S, May MJ, Kopp EB. NF- $\kappa B$ and Rel proteins: evolutionarily conserved mediators of immune response. Annu Rev Immunol 1998; 16: 225-260.

14. Baldwin Jr AS. The NF- $\kappa$ B and $l_{\kappa} \mathrm{B}$ proteins: new discoveries and insights. Annu Rev Immunol 1996; 14: 649-681.

15. Karin M, Cao X, Greten FR, Li Z-W. NF-kappaB in cancer: from innocent bystander to major culprit. Nat Rev Cancer 2002; 2: 301-310.

16. Baumann M, Krause M, Hill R. Exploring the role of cancer stem cells in radioresistance. Nat Rev Cancer 2008; 8: 545-554. Review.

17. Romano S, Mallardo M, Chiurazzi F, Bisogni R, D'Angelillo A, Liuzzi R et al. The effect of FK506 on transforming growth factor beta signaling and apoptosis in chronic lymphocytic leukemia B cells. Haematologica 2008; 93: 75-84

18. Chen AY, Okunieff $P$, Pommier $Y$, Mitchell JB. Mammalian DNA topoisomerase I mediates the enhancement of radiation cytotoxicity by camptothecin derivatives. Cancer Res 1997; 57: $1529-1536$.

19. Kabeya $Y$, Mizushima N, Ueno T, Yamamoto A, Kirisako T, Noda T et al. LC3, a mammalian homologue of yeast Apg8p, is localized in autophagosome membranes after processing. EMBO J 2000; 19: 5720-5728.

20. Chandler JM, Cohen GM, MacFarlane M. Different subcellular distribution of caspase-3 and caspase-7 following Fas-induced apoptosis in mouse liver. J Biol Chem 1998; 273: 10815-10818.

21. Habraken Y, Piette J. NF-kappaB activation by double-strand breaks. Biochem Pharmacol 2006; 72: 1132-1141. Review.

22. Copetti T, Bertoli C, Dalla E, Demarchi F, Schneider C. p65/RelA modulates BECN1 transcription and autophagy. Mol Cell Biol 2009; 29: 2594-2608.

23. Kim H, Rafiuddin-Shah M, Tu HC, Jeffers JR, Zambetti GP, Hsieh JJ et al. Hierarchical regulation of mitochondrion-dependent apoptosis by BCL-2 subfamilies. Nat Cell Biol 2006; 8: $1348-1358$

24. Zhou S, Schuetz JD, Bunting KD, Colapietro AM, Sampath J, Morris JJ et al. The $A B C$ transporter Bcrp1/ABCG2 is expressed in a wide variety of stem cells and is a molecular determinant of the side-population phenotype. Nat Med 2001; 7: 1028-1034.

25. Monzani E, Facchetti F, Galmozzi E, Corsini E, Benetti A, Cavazzin C et al. Melanoma contains CD133 and ABCG2 positive cells with enhanced tumourigenic potential. Eur J Cancer 2007; 43: 935-946.

26. Hocker TL, Singh MK, Tsao H. Melanoma genetics and therapeutic approaches in the 21st century: moving from the benchside to the bedside. J Invest Dermatol 2008; 128: 2575-2595.

27. Poeck H, Besch R, Maihoefer C, Renn M, Tormo D, Morskaya SS. $5^{\prime}$-TriphosphatesiRNA: turning gene silencing and Rig-I activation against melanoma. Nat Med 2008; 14 : 1256-1263.

28. Sinars CR, Cheung-Flynn J, Rimerman RA, Scammell JG, Smith DF, Clardy J. Structure of the large FK506-binding protein FKBP51, an Hsp90-binding protein and a component of steroid receptor complexes. Proc Natl Acad Sci USA 2003; 100: 868-873.

29. Bouwmeester $\mathrm{T}$, Bauch $\mathrm{A}$, Ruffner $\mathrm{H}$, Angrand $\mathrm{PO}$, Bergamini $\mathrm{G}$, Croughton $\mathrm{K}$ et al. A physical and functional map of the human TNF-alpha/NF-kappaB signal transduction pathway. Nat Cell Biol 2004; 6: 97-105.

30. Naumann U, Bähr O, Wolburg H, Altenberend S, Wick W, Liston $P$ et al. Adenoviral expression of XIAP antisense RNA induces apoptosis in glioma cells and suppresses the growth of xenografts in nude mice. Gene Ther 2007; 14: 147-161.

31. Zabierowski SE, Herlyn M. Learning the ABCs of melanoma-initiating cells. Cancer Cell 2008; 13: 185-187.

32. Schatton T, Murphy GF, Frank NY, Yamaura K, Waaga-Gasser AM, Gasser M et al. Identification of cells initiating human melanomas. Nature 2008; 451: 345-349.

33. Baughman G, Wiederrecht GJ, Faith Campbell N, Martin MM, Bourgeois S. FKBP51, a novel T-cell specific immunophilin capable of calcineurin inhibition. Mol Cell Biol 1995; 15: 4395-4402.

34. Benassi B, Zupi G, Biroccio A. Gamma-glutamylcysteine synthetase mediates the c-Mycdependent response to antineoplastic agents in melanoma cells. Mol Pharmacol 2007; 72 : 1015-1023.

35. Trotta PP, Harrison Jr SD. Evaluation of the antitumor activity of recombinant human gamma-interferon employing human melanoma xenografts in athymic nude mice. Cancer Res 1987; 47: 5347-5353.

36. Giard DJ, Aaronson SA, Todaro GJ, Arnstein P, Kersey JH, Dosik H et al. In vitro cultivation of human tumors: establishment of cell lines derived from a series of solid tumors. J Nat/ Cancer Inst 1973; 51: 1417-1423.

37. Franken NAP, Rodermond HM, Stap J, Haveman J, van Bree C. Clonogenic assay of cells in vitro. Nat Protoc 2006; 1: 2315-2319.

38. Staibano S, Pepe S, Lo Muzio L, Somma P, Mascolo M, Argenziano G. Poly(adenosine diphosphate-ribose) polymerase 1 expression in malignant melanomas from photoexposed areas of the head and neck region. Hum Pathol 2005; 36: 724-731. 